\title{
Els diaris com eines de reflexió sobre la pràctica.
}

Pere Jaume Alzina Seguí

Universitat de les Illes Balears (UIB)

Departamento de Pedagogía Aplicada y Psicología de la Educación

pere.alzina@uib.es

Fecha presentación: 10/11/2017 | Aceptación: 30/11/2017 |Publicación: 21/12/2017

\section{Resumen}

Los períodos de prácticas educativas de los estudios de maestro han de servir para reflexionar en profundidad sobre los diferentes aspectos del oficio. En este sentido, los diarios que escribe el estudiante en prácticas deben convertirse en una herramienta de intercambio de conocimientos y de reflexión sobre todo lo que sucede durante este periodo. Los estudiantes en prácticas y el tutor de la universidad deben mantener una relación fluida que permita consolidar los aprendizajes, resolver dudas, compartir experiencias e identificar los aspectos más relevantes que todo maestro debe tener en cuenta. Este artículo profundiza en estos aspectos e intenta demostrar el nivel de sistematización y de reflexión que ésta herramienta puede proporcionar.

Palabras clave: Prácticas, reflexión sobre la práctica, estudios de maestro.

\section{Resum}

Els períodes de pràctiques educatives dels estudis de mestre han de servir per reflexionar en profunditat sobre els diferents aspectes de l'ofici. En aquest sentit, els diaris que realitza l'estudiant en pràctiques ha de ser una eina d'intercanvi de coneixements i de reflexió sobre tot allò que succeeix durant aquest període. L'estudiant en pràctiques i el tutor de la universitat han de mantenir una relació fluïda que permeti consolidar aprenentatges, resoldre dubtes, compartir experiències i identificar els aspectes més rellevants que tot mestre ha de tenir en compte. Aquest article aprofundeix en aquests aspectes i intenta demostrar el nivell de sistematització y de reflexió que aquesta eina pot proporcionar

Paraules clau: Pràctiques, reflexió sobre la pràctica, estudis de mestre.

\begin{abstract}
The periods of educational practices of the teacher's studies should serve to reflect in depth on the different aspects of the trade. In this sense, the journals that the student writes in practice must become a tool for the exchange of knowledge and reflection on everything that happens during this period. The interns and the tutor of the university must maintain a fluid relationship to consolidate learning, answer questions, share experiences and identify the most relevant aspects that every teacher must take into account. This article delves into these aspects and tries to demonstrate the level of systematization and reflection that this tool can provide.
\end{abstract}

Key Words: Practices, reflection on practice, teacher studies. 


\section{Introducció}

Els estudiants de magisteri d'educació infantil i d'educació primària elaboren un setmanari, durant el períodes de pràctiques, on van recollint aprenentatges, dubtes, reflexions, descriuen intervencions i expressen sentiments, sense restriccions ni limitacions. Les accions que s'hi recullen són properes i reals i permeten la reinterpretació del que descriuen, el contrast amb altres pràctiques i la teorització. El paper del tutor de la universitat és molt rellevant en aquest procés de reflexió. Aquests diaris (o setmanaris, el lliuren cada setmana) esdevenen eines de reflexió i de recerca que permeten la millora professional i personal. La recerca que presentem recull l'anàlisi d'una àmplia mostra de diaris i pretén identificar quins són els aspectes més rellevants. Aquests recull de diaris analitzats prové d'estudiants del grau de mestre d'educació primària i d'educació infantil que realitzen les seves pràctiques en centres educatius que reuneixen característiques específiques i amb tutors que també han demostrat les seves bones pràctiques:

- Són centres amb equips de treball consolidats i amb projectes d'innovació en marxa a curt i mitjà termini. Els estudiants en pràctiques s'impliquen en aquests processos d'innovació.

- Com a centre, expressen la clara voluntat de participar en el programa de pràctiques i amb la formació inicial que se portarà a terme. Aquest compromís implica, entre d'altres, l'assumpció del estudiants de pràctiques per part d'equips de cicle.

- $\quad$ El centres de pràctiques s'integren en equips de treball compartit on es pugui visualitzar, plasmar i avaluar la formació permanent amb la formació inicial.

Els tutors i les tutores, per la seva part, assumeixen una forta implicació personal i institucional, en la formació dels futurs mestres, la qual cosa hauria de rebre un reconeixement, que en hores d'ara no rep:

- El tutor de l'escola acompanya l'estudiant en pràctiques en el procés de formació des del disseny i l'aplicació, en l'anàlisi de situacions reals i en el procés de reflexió i interiorització

- El tutor de l'escola representa l'entrada de l'estudiant a la realitat educativa, que li presenta el context i totes les interaccions professionals.

- El mestre tutor comparteix tutoria amb el professor de la universitat i, per tant, té una important responsabilitat en l'itinerari formatiu. Considerem que els diaris de pràctiques són una eina útil d'aprenentatge reflexiu ja que el procés d'escriure representa, en si mateix, una acte de producció de coneixement; escriure també implica un procés de creació i revisió del que ha succeït i ens permet noves mirades, noves comprensions; escriure implica també estructurar molt bé el contingut, establint relacions entre el que es coneix i el que s'està aprenent. Finalment, l'escriptura és molt personal, amarada de subjectivitat, i permet, amb successives devolucions, la reconstrucció de vivències, experiències i sentiments. Estructurar bé una narració sempre ens permet aprendre sobre el que escrivim.

\section{Anàlisi dels diaris de pràctiques}

No existeix un únic model de diari. Les entrades al diari es negocien amb els estudiants i els tutors de centre i de la universitat. Per ser efectius han d'esdevenir un procés de construcció conjunta en el que hom s'hi senti còmode. L'objectiu és aconseguir aprenentatges profunds i rigorosos mitjançant la reflexió i la construcció conjunta del coneixement (Mercer 1997). Per aconseguir aquests aprenentatges profunds cal tenir en compte que:

- Cal compartir els objectius i els indicadors d'observació. Cal consensuar-los i adaptar-los en cada cas. En cada circumstància, en cada context se poden prioritzar objectius i indicadors diferents. En cas contrari, els diaris es converteixen en una tasca burocràtica, on predomina la descripció impersonal.

- Cal assegurar que es fan visibles els pensaments individuals; en cas contrari, els diaris esdevenen tasques irrellevants que l'estudiant no valora perquè li aporta molt poc. Sense reflexió i sense devolucions precises i rigorosos, el diari es buida de contingut.

- Cal assegurar la comprensió del que es treballa; per comprendre cal compartir i dialogar.

- Cal assegurar que els fets que s'analitzen en els diaris i esdevenen objecte d'anàlisi se situen en contextos d'experimentació; en contextos d'acció real.

- Finalment, cal assegurar que s'han consensuat els indicadors i les eines i els indicadors d'avaluació per estructurar adequadament els aprenentatges (Wells 2001) que se'n deriven de l'anàlisi i per tenir clar en quina direcció s'avança conjuntament. Estudiants i tutors han de compartir i visualitzar, de manera clara, allò que volem aconseguir.

Després d'analitzar més d'un centenar de diaris, hem identificar fins a vuit grans categories que reuneixen les condicions esmentades.

\subsection{Compartir per aprendre.}

Junts aprenem més i millor. Considerar l'estudiant en pràctiques com un professional més que aprèn i que, alhora, ensenya és una gran oportunitat per millorar la pràctica educativa, com queda reflectit en aquest fragment:

L'endemà em va proposar que ja que cada dia compartim observacions, reflexions i anècdotes sobre els infants per Drive, que també podiem crear un document de Drive per cadascuna de noltros, i així ho vaig fer. Així que ara, a més de comentar aspectes que considerem importants dels alumnes, també "analitzem" la nostra pràctica! És genial, motivant, molt útil, ... serveix per adquirir molta consciència sobre com ens veiem a nosaltres mateixes, però també per saber com som vistes des d'un altre punt de vista. També serveix per demanar dubtes sobre les nostres intervencions. (R 9-13 març 2015).

Compartir els aprenentatges ens permet aprendre els uns dels altres i construir una sòlida comunitat d'aprenentatge entre els tutors de la universitat, del centre i els estudiants.

\subsection{Analitzar els complexos processos d'ensenyament $i$ aprenentatge.}

Les interaccions múltiples entre els estudiants en pràctiques, les tutores de l'aula i els fillets i les filletes proporcionen oportunitats d'aprenentatge que no 
sempre són aprofitades. Especial rellevància tenen aquelles propostes que provenen dels fillets i de les filletes:

Començo a veure moltes oportunitats de treure suc a converses que esdevenen a l'aula. Per exemple, hi ha un infant al que li interessen molt els mapes, els plànols, ..., també hi ha un altre infant al que li agrada el tema de "la terra" (dia i nit, distàncies, etc.) i quan juga sempre "va de viatge", hi ha un parell d'infants que darrerament han anat de viatge a Sud Amèrica, etc. i a l'aula s'han donat algunes converses que jo crec que estirant un poc podrien donar peu a un bon projecte (R 23- 1 d'abril 2015).

Reflexionar sobre aquestes oportunitats permet enfortir les capacitats de l'estudiant en pràctiques i oferir-li eines per a futures intervencions. La devolució del tutor de la universitat va incloure un parell d'articles que parlaven com construir coneixement a partir del diàleg $\mathrm{i}$ quines són les preguntes més rellevants que permeten una conversa exitosa. El diari esdevé una valuosa eina de reflexió sobre la pràctica i permet a l'estudiant reflexionar sobre el procés d'aprenentatge:

He de dir que m'encanta fer feina en equip i veig que necessito compartir amb na Xelo el què passa a l'aula. És a dir, les observacions, anècdotes, impressions, reflexions, ... A jo em va molt bé per reviure el matí; per tornar sobre una situació i potser adquirir una perspectiva diferent sobre la mateixa; per ser més conscient de les accions, actuacions, dificultats, reptes, aprenentatges, ... dels infants; per revisar la meva pràctica; ... hi ha tantes coses que es remouen cada capvespre quan em poso a escriure... que penso que m'ha creat com una espècie d'addicció. Necessito escriure el què he vist, el què penso, el que m'angoixa, el que m'alegra, ... no m'ho puc quedar per jo! Necessito compartir-ho ${ }^{1}$.

En aquest fragment podem entendre la força narrativa d'una escriptura compromesa, profundament personal, subjectiva però amb grans potencialitats per consolidar aprenentatges.

2.3 Identificar, entendre, comprendre, valorar i aprendre de les dificultats.

Hem de concebre les dificultats com oportunitats de créixer, de madurar professionalment, d'aprendre a

\footnotetext{
${ }^{1}$ I això em fa pensar en com ho fan les mestres que, per diferents motius, no tenen l'oportunitat de compartir amb ningú les seves experiències. Com es poden quedar només per elles el què veuen i el què viuen? Com donen sortida a les seves sensacions, emocions, preocupacions, goigs, etc.? Com es pot ser mestra, tenir tanta responsabilitat a les mans, i no compartir aquesta responsabilitat amb ningú? Com es poden no compartir les alegries i les tristeses? M'angoixa pensar que si un dia faig feina, em pugui trobar en una situació en la que, potser per diferència de criteris o per algun altre motiu, no tingui l'oportunitat de compartir amb un altre professional el què esdevingui a l'aula... penso que em seria realment difícil, i que a la llarga, això podria fer que m'acomodés i que no tingués la necessitat de millorar cada dia, ja que ningú m'acompanyaria en les meves reflexions. (A 11-15 maig 2015)
}

superar situacions adverses, de reconèixer determinades limitacions... Les dificultats, els problemes i les insatisfaccions poden generar canvis en positiu:

Jo sempre he defensat que si un mestre no està bé per fer feina, hauria de ser conseqüent i dedicar-se, durant un temps, a una altra cosa, ja que els infants no poden "pagar" els problemes dels adults. Però mira jo, sense encara ser mestra, ja em trobo en una situació en la que tot i intentar amb totes les meves forces deixar els problemes fora de l'escola, aquests entren amagats a través de la meva autoestima i condicionen la meva conducta. ( $\mathrm{N}$ 20-24 d'abril 2015).

Reconèixer les pròpies limitacions i reflectir-les implica poder posar-hi remei.

Aquesta setmana també he estat conscient que em manquen estratègies en algunes situacions en que he de dirigir el grup, ja que encara em sento un tant insegura en determinades situacions o quan em sento pressionada, i això provoca que hagi de millorar algunes de les meves actuacions (N 12-17 d'abril 2015).

Al cap d'unes setmanes, la situació ha millorat; comparar ambdós fragments ajuda a l'estudiant a prendre consciència de la complexa realitat que viu:

Noto que som capaç de preveure el que pot passar i avançar-m'hi. Aquestes dues darreres setmanes me n'he adonat que tinc més estratègies de les que pensava... tot i que encara me'n falten moltes per adquirir, sí que noto que si quedo amb el grup o surto amb una part d'aquest, puc preveure què pot passar, i com a tal, som capaç de posar en marxa estratègies per fomentar o evitar determinades situacions (...).es fa imprescindible observar i escoltar al grup, mirar-lo, saber com funciona, ... però sense etiquetar i sent flexibles, ja que els canvis que es donen en els infants, i per tant en el grup, són constants i molt diversos. Saber què podem esperar, però sempre amb una porta oberta a la improvisació. (N 27-8 maig 2015).

Les dificultats que experimentem com a professionals són les mateixes que els fillets i les filletes d'una aula poden presentar al davant de determinats aprenentatges. Aprofundir en la seva naturalesa, intentar comprendre-les $i$ actuar en conseqüència pot donar, a mitjà termini, importants fruïts:

He estat profundament preocupada pel bloqueig emocional d'un fillet que no vol parlar. He intentat aproximar-m'hi de moltes maneres, però sempre acabava en negativa o rebuig. Un dia, mentre estaven escrivint el títol d'un conte, anava passant per les taules per ajudar-los. El fillet estava aturat i dubtava si escriure o no. Vaig provar d'ajudar-lo, escrivint la primera lletra del títol, sense dir-li res. Em va mirar i va somriure. Va saber continuar. Va ser meravellós. Havia aconseguit rompre el bloqueig (P 27-8 maig 2015). 
Aprendre reflexionant conjuntament sobre les dificultats $i$ els errors, els nostres i els dels nostres estudiants, ens permet dissenyar accions i intervencions més precises, més acurades i més ajustades a les necessitats de les persones que aprenen, siguin fillets o professionals. L'error ha de ser benvingut com oportunitat d'aprenentatge. Descartem el coneixement incorrecte (Hattie 2012)

\subsection{Aspectes metodològics.}

Gran part de les entrades als diaris fan referència, com és lògic, a les programacions, al currículum, a la gestió del temps i de l'espai, a l'avaluació (documentar, valorar, qualificar, jutjar....... Reflexionar sobre l'organització i la gestió de l'aula permet identificar els punts claus que sustenten una intervenció de qualitat:

Està tot molt organitzat, però amb moltíssima flexibilitat i respecte. Na Concepció demostra una paciència i respecte cap a tots i cadascun dels infants que és impressionant! M'encanta! Respecta les seves intervencions, produccions, jocs, ...

Els dóna veu i ells ho aprofiten amb molta responsabilitat, argumentant les seves intervencions i defensant la seva opinió. $\mathrm{Na}$ Concepció s'hi comunica amb un llenguatge molt ric i es nota en la manera que ells tenen d'expressar-se i argumentar les seves opinions. S'aprofiten totes i cadascuna de les situacions per generar aprenentatges. Es fomenta l'autonomia i se'ls anima a provar per ells mateixos. Si demanen ajuda no se'ls hi nega, però se'ls anima a provar-ho ells, acompanyantlos i oferint ajudes puntuals si és necessari ( $M$ 9-13 febrer 2015).

Un dels aspectes que més preocupen és la gestió del temps. Sembla com si mai no hagués suficient temps per fer el que es voldria fer, per portar a terme tots els projectes iniciats, per endegar tots els processos... Fins al punt, que convertim l'aula, en determinats moments i períodes del curs, en un lloc d'activitat frenètica intentant acabar, oblidant-nos de la serenor que requereix tot aprenentatge profund, totes les feinetes iniciades. Una bona anàlisi de la situació permet identificar aquells aspectes que caldria millorar:

On és la calma que defensem que hi hauria d'haver a les aules? Hem llegit, escoltat, reflexionat en nombroses ocasions sobre l'educació lenta, sobre aprofitar el kairós en comptes d'estar pendent del cronos, però en el dia a dia això no sempre és així. La programació (la qual considero moltíssim necessària, sempre i quan aquesta accepti canvis i sigui flexible) l'atapeïm d'activitats; sembla que tenim por que els infants s'avorreixin... i al final, el que passa, és que generalment mai s'acaba duent a terme tota la programació. I això no ho veig un problema perquè interpreto que és que ens hem sabut adaptar a les necessitats, ritmes o demandes dels infants i hem estat flexibles, però això provoca que després ens quedem amb la sensació que no arribem a tot, quan potser el problema és que la programació és massa ambiciosa (N 16-20 març 2015).
Si l'estudiant en pràctiques comparteix aquestes reflexions amb la tutora de l'aula, de ben segur (com va ser el cas) que la situació es pot reorientar.

Un dels aspectes més rellevants del procés d'ensenyament i aprenentatge és generar una bona documentació que ens permeti analitzar, en perspectiva, tot el succeït. Tenim a la nostra disposició moltes eines de documentació, la fotografia n'és una d'elles:

I ja sabem que aquestes són molt important per donar valor al què es fa, però és que ja no és sa foto en sí, sinó que quan tu agafes sa càmera ja focalitzes la mirada i, encara que no facis sa foto, ja estàs donant valor a allò que fa l'infant perquè l'estàs observant més a fons, et fixes en els detalls, hi aprofundeixes, ... i adquireixen molta més consciència de com és el procés que fa aquell fillet o filleta per dur a terme una determinada acció. (A 16-20 febrer 2015).

Fer conscients de la necessitat de ben documentar els processos permet entendre i enfocar l'avaluació des de noves perspectives. Determinades formes d'avaluar, com fer proves individuals, poden recollir dades poc significatives i allunyades de la realitat.

\begin{abstract}
Considero que el seu estat de desenvolupament encara no li permet mostrar interès per determinats aprenentatges, sobretot en segons quins moments, i més després d'haver estat desconnectat de l'escola durant més d'un mes. Com ha de demostrar que recorda com ha d'escriure el seu nom després d'un mes sense fer-ho, quan se li demana que ho faci sense cap motiu més que perquè na Maru ho diu, i quan se li demana el temps de pati mentre els companys són fora jugant? Per jo no és significatiu ni vinculant, aquest registre! Què passa, que és més vàlida l'observació feta a partir d'un registre d'avaluació fet fora de context que una observació feta a partir d'una tasca que jo considero bastant més significativa? (L 12-17 abril 2015).
\end{abstract}

Fer conscient d'aquesta situació a l'estudiant en pràctiques i a la tutora d'aula permet millorar els processos de recollida de dades i de documentació i permet obtenir una imatge més ajustada dels processos d'aprenentatge de tots els fillets.

\subsection{Aprendre a identificar els aspectes validats per la ciència $\mathrm{i}$ la recerca.}

Contrastar i validar determinades pràctiques amb els resultats de la recerca és un dels eixos que guien les reflexions dels diaris de pràctiques. Compartir lectures, articles i recerques permet millorar la pràctica:

Les propostes plàstiques també es modificaran. També lligat a aquest canvi i arran d'un article que n'Marga va compartir amb noltros, hem decidit que ses propostes plàstiques han d'estar diversificades entre algunes més pautades (és així com s'havia fet fins ara), i altres més lliures i experimentals, deixant que ells puguin emprar aquestes experiències per expressar sentiment, necessitats, vivències, ... 
assajar, equivocar-se, xalar, ... i treure el seu potencial a la seva manera. No sempre esperant una determinada producció o producte. (P 9-13 març 2015).

La relació amb les famílies és un aspecte cabdal; reflexionar-hi a partir de lectures és una bona estratègia per evitar intervencions precipitades:

La tutora demostra tenir molt bona relació amb ses famílies. La mestra verbalitza que és important guanyar-nos la seva confiança! No els critica, ni els vol contentar perquè sí, sinó que té en compte la seva opinió i cerca estratègies perquè allò que els ha molestat no torni a passar. Si les famílies confien en nosaltres, l'infant ho nota i ell és el màxim beneficiari. He pogut aportar una reflexió d'una lectura en la qual diu que l'ordre natural i correcte és que primer hi ha la família, i que els mestres anem després. (A 9-13 febrer 2015).

Compartir articles, recerques i opinions, permet consolidar la pròpia opció metodològica:

La setmana passada vaig llegir un article sobre la lectoescriptura i el vaig passar a tot el cicle, ja que tot i no dir res de nou, vaig pensar que estava molt ben argumentat i explicat: quan el llegia estava pensant precisament en aquests infants, i quan la mestra el va llegir es veu que li va passar el mateix. Em vaig sentir satisfeta perquè en vam poder xerrar i ella va verbalitzar que potser els havia de donar més temps i no forçar-los davant determinades feines, i hi estic totalment d'acord. (L 23-1 abril 2015).

Aquestes aportacions permeten millorar la coordinació entre la universitat $\mathrm{i}$ els seus tutors, els tutors de pràctiques $i$ els estudiants. Els tres es troben en contextos d'aprenentatge i de contrast d'idees.

\subsection{Importància d'acollir els estudiants en pràctiques}

És molt important que l'equip directiu aculli i realitzi un seguiment dels estudiants en pràctiques i assegurar la seva participació en tots els òrgans de decisió del centre; els estudiants ho agraeixen i se sentin partícips de la vida del centre:

Per jo també va ser important que ella es preocupés per com ens sentim a l'escola i amb les nostres tutores, si ens fa falta res, si hi ha alguna cosa que puguin fer des del centre per ajudar-nos, ... ens va mostrar preocupació i ens va oferir suport i ajuda. A jo em va demostrar que una preocupació de l'equip directiu és el benestar de les persones que formen part del centre, i això, a nivell de centre, ho considero molt positiu. (P Arran d'una reunió amb la cap d'estudis 16-20 març 2015).

Els estudiants en pràctiques han de ser considerats com membres del claustre a tots els efectes i participar en les reunions de cicle, d'etapa, en la CCP, en els claustre i en totes les comissions del centre. També és important establir una bona relació amb el personal no docent.

\subsection{Importància de valorar les iniciatives dels estudiants} en pràctiques.

Al llarg del període de pràctiques, els estudiants han d'assumir (durant tres setmanes o un mes) la plena gestió de l'aula. Durant aquest període, d'acord amb la tutora, poden incloure innovacions i dissenyar activitats en el marc de la programació del cicle. La gestió plena de l'aula els dóna confiança i els permet experimentar com serà la seva vida professional:

Per altra banda, entre dimarts i dimecres vam canviar el material del racó de construccions, ja que des de principi de curs no s'havia canviat, i alguns infants ja no feien un ús adequat del material. Va ser emocionant pensar i cercar el material que els podia anar bé, que els podia provocar reptes, que els convidés a construir de manera diferent a com ho havien vingut fent fins ara, ... Vaig veure tant clars els processos que anaven fent mentre interactuaven amb aquest material, que vaig xalar com mai! Em vaig emocionar molt, tant que quan va venir na Maru i li vaig voler explicar el què havia passat, em van caure les llàgrimes. Plorava d'emoció pel que havia gaudit, per la satisfacció de pensar que el material era adequat (al manco per a aquests infants), de pensar que la nostra proposta havia provocat nous reptes i noves adquisicions en ells, que havien jugar de manera cooperativa, concentrats, relaxats, etc. Va ser una sensació indescriptible. Per sort, vaig fer moltes fotos per poder-ho reviure, així com documentar i compartir amb na Maru ( $\mathrm{L}$ 12-17 abril 2015).

Gaudir d'aquestes sensacions, sentiments i emocions ajuda a construir una imatge ajustada d'un mateix i de les seves possibilitats. Una estudiant va proposar una interessant iniciativa que va resultat ser un èxit: el dia sense rellotges i sense programació:

Aquesta setmana s'ha iniciat un camí important perquè la jornada de divendres (dia sense rellotges ni programació), en general, considero que va ser un èxit. Mentre estic escrivint aquest setmanari, vaig seguint les aportacions i reflexions que, fins el moment, estem compartint na Anni, na Concepció i jo per Drive, i són genials! Totes en fem una valoració molt positiva, les nostres paraules demostren emoció, entusiasme, sorpresa, engrescament, motivació, ... i espero que aquestes puguin ser degudament recollides i transformades en canvis, encara que sigui a llarg termini. (M 1822 maig 2015).

Aquesta passió és reflectida en la recerca: aquesta passió no és misteriosa, se relaciona amb el nivell d'entusiasme que mostra el professor, el grau de comunicació amb cada estudiant i amb el mateix procés d'ensenyament i aprenentatge (Steele 2009)

\section{8}

Finalment, apuntem un darrer aspecte rellevant: la raó (cognició, coneixement), l'emoció i els principis ètics s'han de treballar alhora en situacions contextualitzades, complexes, engrescadors i reptadores.

La recerca apunta que la variable aïllada que més 
Alzina Seguí, Pere Jaume. “Els diaris com eines de reflexió sobre la pràctica”. @tic. revista d'innovació educativa. Número 19. Otoño (julio-diciembre 2017), pp. 10-15

influeix en un aprenentatge profund és la implicació, el que en anglès es coneix com student engagement (Coates, Hamish, McCormick 2014): el temps i l'esforç que els estudiants dediquen a activitats valuoses des del punt de vista educatiu. Aquestes activitats valuoses impliquen una mobilització dels coneixements, les emocions i les actituds en tasques contextualitzades amb molt potencial:

Abraçar-los (sempre demanant permís) si ho necessiten, oferir-los una mà (o les dues!), ferlos una broma per treure'ls un somriure, brindar-los ajuda, animar-los a ser autònoms, confiar en ells, ... en fi, tenir-los en compte i donar-los el millor que tenim: el nostre temps i la nostra atenció des del respecte, és impressionant perquè ells ho perceben $\mathrm{i}$ et retornen el que tu els has donat, però multiplicat per molt! Es nota que ho agraeixen i llavors és quan notes que el què fem val molt la pena! (A 23-26 febrer 2015).

Aquest darrer paràgraf ens permet adonar-nos de la importància de dissenyar situacions potents d'ensenyament i aprenentatge que tinguin en compte els sentiments i les emocions, les actituds i els coneixements de les persones que aprenen, sigui quina sigui la seva edat.

\section{Conclusions}

Cal que les condicions que envolten la formació dels futurs mestres es converteixin en espais d'interrogació reflexiva, en espais on compartir coneixements, on reviure experiències que ens enriqueixin a tots, treballant cooperativament entre els tutors de la universitat, els tutors dels centres educatius i els estudiants en pràctiques. A partir de l'anàlisi dels diaris de pràctiques hem volgut demostrar que ens cal orientar la formació cap un enfocament reflexiu sobre la pràctica que

- $\quad$ Els permeti analitzar el transcurs i significat de les accions en la seva aula durant el període de pràctiques.

- Els permeti identificar els processos i els resultats; els estudiants han de saber llegir més enllà del que són capaços d'observar a través dels sentits; els estudiants han de saber endinsar-se en els sentiments i les emocions de les persones i saber-les interpretar en contextos d'acció.

- Els permeti identificar les limitacions i els costos de l'acció: és l'acció més adient a la situació plantejada? Valdrà la pena dissenyar aquesta tasca? Serà realment potent i assegurarà un aprenentatge profund? Els estudiants en pràctiques han d'aprendre a intervenir adequadament però també a esperar; cal aprendre a confiar amb els fillets $i$ les filletes i amb les seves capacitats i possibilitats.

- Els permeti avaluar el que ha programat i analitzar el que ha succeït. Els processos de valoració i d'avaluació són determinants per conèixer l'abast les actuacions dissenyades i permeten reorientar l'acció. Hem d'entendre les dificultats com oportunitats de millora.

- Finalment, aquest enfocament profundament reflexiu els permetrà posar en pràctica millores contrastades a partir d'evidències empíriques, fruit de l'anàlisi cooperatiu i de la reflexió conjunta.

Per aconseguir aquesta formació transformadora necessitem professors universitaris reflexius, que formin part de comunitats d'aprenentatge més àmplies que entengui la pràctica com a praxis reflexiva. Aquests professors s'han de percebre permanentment en formació, com investigadors des de la pràctica mitjançant la indagació sistemàtica i autocrítica fonamentada en la curiositat i el desig de comprendre-la i millorar-la. Cal arribar a una transformació de l'enteniment sobre el que es fa i adquirir consciència del canvi. Se'ns dibuixa un professor universitari, formador de mestres, conscient, orientat a l'evolució i millora personal, orientat a servir de guia i de model per als estudiants i compromès en la millora i el benestar de la comunitat.

\section{Referències}

Coates, H.; McCormick, A. C. (eds.) (2014). Engaging University Students. Springer Singapore.

Hattie, J. (2012). Visible learning for teachers. Maximizing impact on learning London: R. T. F. Group.

Mercer, N. (1997). La construcción guiada del conocimiento. El habla de profesores y alumnos Barcelona: Paidós.

Steele, C. F. (2009). The inspired teacher: how to know one, grove one, or be one. Alexandria: ASCD.

Wells, G. (2001). Indagación dialógica. Hacia una teoría y una práctica socioculturales de la educación. Barcelona: Paidós.

| Cita recomendada de este artículo

Alzina Seguí, Pere Jaume. (2017). “Els diaris com eines de reflexió sobre la pràctica”. en @tic. revista d'innovació educativa. Número 19. Otoño (Julio-Diciembre 2017), pp. X-X. 